\title{
Effects of folic acid food fortification scenarios on the folate intake of a multi-ethnic pregnant population
}

Juliana A Teixeira ${ }^{1,2}$, Teresa G Castro ${ }^{2,3}$, Clare R Wall ${ }^{2,4}$, Dirce Maria Marchioni ${ }^{1}$, Sarah Berry ${ }^{2}$, Susan MB Morton ${ }^{2}$ and Cameron C Grant ${ }^{2,3,5, *}$

${ }^{1}$ Department of Nutrition, School of Public Health, University of São Paulo, São Paulo, Brazil: ${ }^{2}$ The Centre for Longitudinal Research - He Ara ki Mua, School of Population Health (building 730, level 3), Tamaki Campus, University of Auckland, 261 Morrin Road, St Johns, Auckland 1072, New Zealand: ${ }^{3}$ Department of Paediatrics: Child and Youth Health, University of Auckland, Auckland, New Zealand: ${ }^{4}$ Discipline of Nutrition and Dietetics, School of Medical Sciences, University of Auckland, Auckland, New Zealand: ${ }^{5}$ Starship Children's Hospital, Auckland District Health Board, Auckland, New Zealand

Submitted 27 April 2018: Final revision received 9 September 2018: Accepted 1 October 2018: First published online 5 December 2018

\begin{abstract}
Objective: To simulate effects of different scenarios of folic acid fortification of food on dietary folate equivalents (DFE) intake in an ethnically diverse sample of pregnant women.

Design: A forty-four-item FFQ was used to evaluate dietary intake of the population. DFE intakes were estimated for different scenarios of food fortification with folic acid: (i) voluntary fortification; (ii) increased voluntary fortification; (iii) simulated bread mandatory fortification; and (iv) simulated grains-and-rice mandatory fortification.

Setting: Ethnically and socio-economically diverse cohort of pregnant women in New Zealand.

Participants: Pregnant women ( $n$ 5664) whose children were born in 2009-2010. Results: Participants identified their ethnicity as European (56.0\%), Asian (14.2\%), Māori (13.2\%), Pacific (12.8\%) or Others (3.8\%). Bread, breakfast cereals and yeast spread were main food sources of DFE in the two voluntary fortification scenarios. However, for Asian women, green leafy vegetables, bread and breakfast cereals were main contributors of DFE in these scenarios. In descending order, proportions of different ethnic groups in the lowest tertile of DFE intake for the four fortification scenarios were: Asian (39-60\%), Others (41-44\%), European (31-37\%), Pacific (23-26\%) and Māori (23-27\%). In comparisons within each ethnic group across scenarios of food fortification with folic acid, differences were observed only with DFE intake higher in the simulated grains-and-rice mandatory fortification $v$. other scenarios.

Conclusions: If grain and rice fortification with folic acid was mandatory in New Zealand, DFE intakes would be more evenly distributed among pregnant women of different ethnicities, potentially reducing ethnic group differences in risk of lower folate intakes.
\end{abstract}

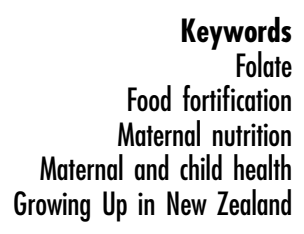

Neural tube defects (NTD) are the second most common birth defect ${ }^{(1,2)}$. The average global birth prevalence of NTD is $2 \cdot 4$ per 1000 live births ${ }^{(1,3,4)}$, with this prevalence varying from $0 \cdot 2$ to 10 per 1000 live births by geographical location $^{(1)}$. NTD constitute an important public health problem in terms of mortality, morbidity, human suffering and societal costs ${ }^{(2)}$. The aetiology of NTD is multifactorial and includes a combination of genetic predisposition and environmental factors ${ }^{(1)}$. The known environmental risk factors for NTD include maternal obesity ${ }^{(5)}$, diabetes ${ }^{(6)}$, hyperthermia during early pregnancy ${ }^{(7)}$, exposure to the fungal product fumonisin ${ }^{(8)}$, anticonvulsant drug use (valproic acid) ${ }^{(9)}$, and vitamin $\mathrm{B}_{12}$ and folate deficiency ${ }^{(1,3,4)}$.

The demonstration of the association of maternal folate status with NTD constituted an important epidemiological achievement $^{(3,4)}$. In 1991, a placebo-controlled trial undertaken by the Medical Research Council (UK) confirmed the protective effect of pre-pregnancy folic acid supplementation against NTD for those women at high risk due to a previous affected pregnancy ${ }^{(9)}$. As a result, many countries 
have implemented maternal folic acid supplementation in the pre-pregnancy period and first trimester of pregnancy. However, despite this intervention the prevalence of NTD did not decrease in the succeeding decade ${ }^{(10,11)}$.

The subsequent implementation of mandatory fortification of cereals with folic acid in some countries, such as the USA, Canada and Chile, resulted in a decreased incidence of NTD ${ }^{(12-14)}$. However, in many European and Asian countries and in New Zealand (NZ), mandatory fortification of food with folic acid was not implemented $^{(12,13,15)}$. Food Standards Australia New Zealand recommended the mandatory fortification of bread with folic acid from 2009; however, in 2012 NZ put this recommendation on hold and revoked the mandatory programme due to concerns about safety, costeffectiveness and impact on consumer choice ${ }^{(16,17)}$. Instead, NZ continued with the voluntary fortification of breads at a level of $200 \mu \mathrm{g}$ folic acid/100 g bread. The industry committed to fortify at least $25 \%$ and up to $50 \%$ of bread production. According to the first audit report to the Ministry for Primary Industries in 2012 and 2013, about $14 \%$ of packaged sliced breads were fortified with folic acid, with plans for $25-35 \%$ by the end of $2014^{(17)}$. Recently (June 2018), the NZ Office of the Prime Minister's Chief Science Advisor and the Royal Society Te Apārangi published a report which provided compelling evidence that the benefits of mandatory fortification of packaged bread with folic acid outweigh any potential adverse effects. This report recommends the mandatory fortification of breads ${ }^{(18)}$.

Fortification of widely distributed and consumed foods with folic acid has the potential to improve the nutritional status of a large proportion of the population, including women of childbearing age ${ }^{(19)}$. This cost-effective public health intervention requires neither changes in dietary behaviours nor individual decisions for compliance ${ }^{(19,20)}$. However, to choose the most effective food vehicle to fortify with folic acid, the dietary patterns of the target population need to be known ${ }^{(20,21)}$. Currently, there is a lack of published data about the most suitable foods for fortification with folic acid in a population of pregnant women from diverse ethnicities, in countries where mandatory fortification is still recent or under consideration.

The objectives of the present study were to: (i) describe the dietary intake of the known main food sources of folate in an ethnically and socio-economically diverse cohort of pregnant women from NZ; and (ii) simulate the potential impact of different scenarios of folic acid fortification on the pregnant women's dietary folate intake.

\section{Methods}

\section{Population and study design}

We completed this project within the Growing Up in New Zealand (GUiNZ; www.growingup.co.nz) cohort study.
GUiNZ is a nationally representative birth cohort study that was created by the enrolment of a large ethnically diverse sample of pregnant women living in $\mathrm{NZ}^{(22)}$. In total, 6822 pregnant women were recruited into the cohort. The 6853 children that formed the birth cohort will be followed until adulthood. Eligibility of women for enrolment was defined by having an estimated delivery date between 25 April 2009 and 25 March 2010 and residence in a geographic region defined by the three contiguous District Health Boards of Auckland, CountiesManukau and Waikato. This region was chosen because of its ethnic, socio-economic and rural/urban diversity. For the present study we used data from the antenatal enrolment interview. This collection wave consisted of a faceto-face home interview conducted with the pregnant women, most often in the last trimester of pregnancy.

Ethical approval was granted by Ministry of Health Northern Y Regional Ethics Committee. Written informed consent was obtained from all participating women.

\section{Assessment and estimation of dietary intake}

The dietary intake was assessed using a semi-quantitative forty-four-item FFQ which referred to the previous four weeks. To reduce recall bias, only data from the women who completed the interview prior to the birth of their child were included ( $n 5664 / 6822,83 \%$ ). As described previously, this FFQ was developed to evaluate the adherence of the study participants to the NZ Ministry of Health guidelines for healthy pregnant women, which encompass recommendations for the intake of four core food groups: fruits and vegetables; breads and cereals; milk and milk products; and lean meat, meat alternatives and eggs ${ }^{(23,24)}$. For each of the forty-four food items, the mothers were asked: 'Which of the following items have you eaten over the last four weeks?' (yes or no) and 'How many servings of this item have you eaten over the past four weeks?' (with frequency options gradually increasing from 1 serving per month to 6 or more per day). The format of the GUiNZ FFQ questions were based in the 2008/09 NZ Adult National Nutrition Survey ${ }^{(25)}$. Show cards with pictures of standard serving sizes were used to help mothers to describe the portion size consumed ${ }^{(24,26)}$. The NZ Ministry of Health guidelines for healthy pregnant women include recommendations for consumption of an adequate amount of folate. The 1997 National Nutritional Survey identified that the main food sources of folate for women aged 25-44 years in New Zealand are vegetables $(18 \%)$, breads (13\%), breakfast cereals (11\%) and fruit $(9 \%)^{(27)}$. A smaller regional survey completed in $2008-$ 2009 reported similar findings where the five largest food contributors of total dietary folate equivalents (DFE) intake were bread (33\% of total DFE), cereal (11\%), vegetables $(10 \%)$, fruit $(7 \%)$ and yeast spread $(5 \%)^{(16)}$. These food items were included in the FFQ used in the GUiNZ study. When pregnant women were recruited into the GUiNZ 
study, NZ did not have mandatory folic acid fortification of the food supply. Therefore, the FFQ used in the GUiNZ study includes the main food sources of folate for pregnant women in NZ and has captured the main dietary folate sources in the NZ food supply.

The present study focused on the dietary intake of foods that are naturally high in folate, or that are fortified or suitable for fortification with folic acid. These include citrus fruit, green leafy vegetables, fruit juices and drinks, yeast spread, bread, breakfast cereals, and noodles, rice and pasta $^{(19,22)}$. The serving sizes were derived from the NZ Food and Nutrition Guidelines for Healthy Pregnant and Breastfeeding Women (Table 1) ${ }^{(23)}$. Daily intakes (grams) of each food item cited above were calculated by multiplying the portion size by the frequency of intake (number of servings consumed per person per day) reported in the FFQ. Bread intake was calculated by summing the items: white bread, high-fibre white bread, brown/wholemeal/ wholegrain bread and other bread. It was not possible to evaluate the items noodles, rice and pasta separately, as they constituted a single food item in the FFQ.

The NZ Food Composition Tables $2009^{(28)}$ were used to calculate the mean DFE content of each food item and also the DFE intake of each participant at the time that the antenatal interview took place, constituting the 'voluntary fortification 2009' scenario (Table 1). For the year 2016, the calculation of the mean DFE content of the food items under investigation used the NZ Food Composition Tables $2016^{(29)}$, with this defined as the increased voluntary fortification 2016' scenario (Table 1). The NZ Food Composition Tables are regularly updated and expanded to include local appropriate food composition values ${ }^{(28,29)}$. DFE describe the dietary folate content of food and account for differences in the absorption of naturally occurring food folate and the more bioavailable synthetic folic acid (naturally occurring food folates plus (folic acid multiplied by 1.67)) ${ }^{(29)}$.

We then studied a third scenario, 'simulated bread mandatory fortification 2016', as initially proposed by the Food Standards Australia New Zealand, which states that bread must contain no less than $80 \mu \mathrm{g}$ and no more than $180 \mu \mathrm{g}$ of folic acid (median $=130 \mu \mathrm{g}$ ) per $100 \mathrm{~g} \mathrm{bread}^{(30)}$. This simulation used as its reference the DFE content of the NZ Food Composition Tables 2016 (29) and set the bread content of DFE at $130 \mu \mathrm{g} / 100 \mathrm{~g}$ bread (Table 1).

Due to increased migration to NZ in recent years ${ }^{(31)}$, NZ has experienced an increase in its cultural diversity and consequently variability in the types of foods eaten ${ }^{(32)}$. Therefore, the fortification of just bread with folic acid might not be sufficient to achieve adequate levels of folate in the target population ${ }^{(33)}$. Therefore, we created a fourth scenario, 'simulated grains-and-rice mandatory fortification 2016', which simulated the DFE intake with the fortification of bread ( $130 \mu \mathrm{g}$ folic acid/100 g) as well as of noodles, rice and pasta ( $113 \mu \mathrm{g}$ folic acid/100g). The scenario's nomenclature and the amount of DFE considered for noodles, rice and pasta in this simulation were based on those established in the USA ${ }^{(34)}$. The reference for the DFE content of the other items was the NZ Food Composition Tables 2016 (Table 1) ${ }^{(29)}$.

The brands and types of breads consumed by the women were unknown as this level of detail was not included in the FFQ. Therefore, the DFE content of breads in 2009 was estimated as the total mean content of DFE of all breads available in the NZ Food Composition Tables 2009. A similar procedure was adopted to estimate the content of DFE from breads in 2016, having as the reference the mean DFE content of all types and brands of breads from the NZ Food Composition Tables 2016.

Figure 1 summarizes the scenarios of food fortification with folic acid considered in the present study and Table 1 shows the portion sizes and DFE values considered to calculate the DFE intake of each study participant.

\section{Assessment of covariates}

The sociodemographic covariates assessed were maternal self-prioritized ethnicity, age, education and BMI, and neighbourhood deprivation.

Detailed information about maternal self-prioritized ethnicity was coded into six Level 1 categories following the Statistics New Zealand coding criteria: (i) European; (ii) Māori; (iii) Pacific Peoples; (iv) Asian; (v) Middle Eastern, Latin American and African (MELAA); and (vi) Other. MELAA and Other were combined for analysis purposes (and designated Others) due to the small number of participants in these groups. Age was categorized as $<20,20-29$ and $>29$ years. Neighbourhood deprivation was described using the 2006 NZ Index of Deprivation (NZDep06), grouped as deciles. These deprivation deciles were then grouped as 1-3 (least deprived), 4-7 and 8-10 (most deprived). NZDep06, derived from 2006 census data on nine socio-economic characteristics, is a well-validated measure of socio-economic deprivation in $\mathrm{NZ}^{(35)}$.

BMI was calculated and categorized according to WHO criteria $^{(36)}$, based on women's self-reported weight (in kilograms) and height (in centimetres). Self-reported information on height and weight during pregnancy has been shown to classify most women appropriately into BMI categories ${ }^{(37)}$.

\section{Statistical analysis}

The prevalence of non-intake of citrus fruit, green leafy vegetables, yeast spread, bread, breakfast cereal (highfibre and others), fruit juices and drinks, and noodles, rice and pasta was described according to each woman's sociodemographic characteristics. The $\chi^{2}$ test identified statistical differences in the prevalence of non-intake according to maternal sociodemographic characteristics.

The DFE provided by each food item was divided by the total DFE (the sum of the studied food items) to obtain the contribution of each food item to the total DFE intake, 
Table 1 Serving size according to the New Zealand (NZ) Food and Nutrition Guidelines for Healthy Pregnant and Breastfeeding Women, dietary folate equivalents (DFE) content (mean) according to the NZ Food Composition Tables (2009 and 2016) for foods naturally high in folate, fortified or suitable for fortification with folic acid, percentage of increase for $2016 \mathrm{v}$. 2009 , and DFE content assumed for the simulated mandatory fortification scenarios. New Zealand, 2008-2010

\begin{tabular}{|c|c|c|c|c|c|c|c|}
\hline \multirow[b]{4}{*}{ Food item } & \multirow{3}{*}{\multicolumn{2}{|c|}{$\begin{array}{c}\text { NZ Food and Nutrition Guidelines for Healthy Pregnant } \\
\text { and Breastfeeding Women* }\end{array}$}} & \multicolumn{2}{|c|}{ Scenario } & \multirow[b]{3}{*}{$\begin{array}{c}\text { Percentage } \\
\text { increase } \\
2016 \text { v. } 2009\end{array}$} & \multicolumn{2}{|c|}{ Scenario } \\
\hline & & & 1 & 2 & & 3 & 4 \\
\hline & & & $\begin{array}{l}\text { 'Voluntary } \\
\text { fortification } \\
2009 ' †\end{array}$ & $\begin{array}{l}\text { 'Increased } \\
\text { voluntary } \\
\text { fortification } \\
2016 ’ \ddagger\end{array}$ & & $\begin{array}{l}\text { 'Simulated } \\
\text { bread } \\
\text { mandatory } \\
\text { fortification } \\
2016 \text { ' }\end{array}$ & $\begin{array}{l}\text { 'Simulated } \\
\text { grains-and-rice } \\
\text { mandatory } \\
\text { fortification } \\
2016 \text { ' }\end{array}$ \\
\hline & Description & $\begin{array}{l}1 \text { serving } \\
(\mathrm{g})\end{array}$ & $\begin{array}{l}\text { Mean in } 100 \mathrm{~g} \\
\quad(\mathrm{DFE}, \mu \mathrm{g})\end{array}$ & $\begin{array}{l}\text { Mean in } 100 \mathrm{~g} \\
(\mathrm{DFE}, \mu \mathrm{g})\end{array}$ & $(\%)$ & $\begin{array}{c}\text { Assumed } \\
\text { DFE } \\
\text { content } \\
\text { in } 100 \mathrm{~g}(\mu \mathrm{g}) \\
\end{array}$ & $\begin{array}{c}\text { Assumed } \\
\text { DFE } \\
\text { content } \\
\text { in } 100 \mathrm{~g}(\mu \mathrm{g}) \\
\end{array}$ \\
\hline Citrus fruit & 1 orange & 130 & 9 & 19 & 111 & $19 \ddagger$ & $19 \ddagger$ \\
\hline $\begin{array}{l}\text { Green leafy } \\
\text { vegetables }\end{array}$ & $\begin{array}{l}1 / 2 \text { cup cooked vegetables (e.g. broccoli, peas, corn, spinach, pūhā) or } \\
1 / 2 \text { cup salad }\end{array}$ & 65 & 71 & 94 & 32 & $94 \ddagger$ & $94 \ddagger$ \\
\hline $\begin{array}{l}\text { Fruit juices and } \\
\text { drinks }\end{array}$ & 1 cup fruit juice & 250 & 6 & 9 & 64 & $9 \ddagger$ & $9 \ddagger$ \\
\hline Yeast spread & 1 teaspoon & 7 & 2000 & 2950 & 48 & $2950 \ddagger$ & $2950 \ddagger$ \\
\hline Bread & 1 medium slice of bread or 1 roll & 38 & 69 & 86 & 25 & 130 & 130 \\
\hline $\begin{array}{l}\text { Breakfast cereal } \\
\text { (high-fibre) }\end{array}$ & 2 breakfast wheat biscuits, $1 / 2$ cup muesli & 45 & 197 & 344 & 75 & $344 \ddagger$ & $344 \ddagger$ \\
\hline $\begin{array}{l}\text { Breakfast cereal } \\
\text { (others) }\end{array}$ & 1 cup cornflakes & 30 & 203 & 316 & 56 & $316 \ddagger$ & $316 \ddagger$ \\
\hline $\begin{array}{l}\text { Noodles, rice and } \\
\text { pasta }\end{array}$ & 1 cup cooked pasta or rice & 150 & 4 & 7 & 59 & $7 \ddagger$ & 113 \\
\hline
\end{tabular}

${ }^{*}$ Ministry of Health (2006) ${ }^{(23)}$

New Zealand Ministry of Health ${ }^{(29)}$. 


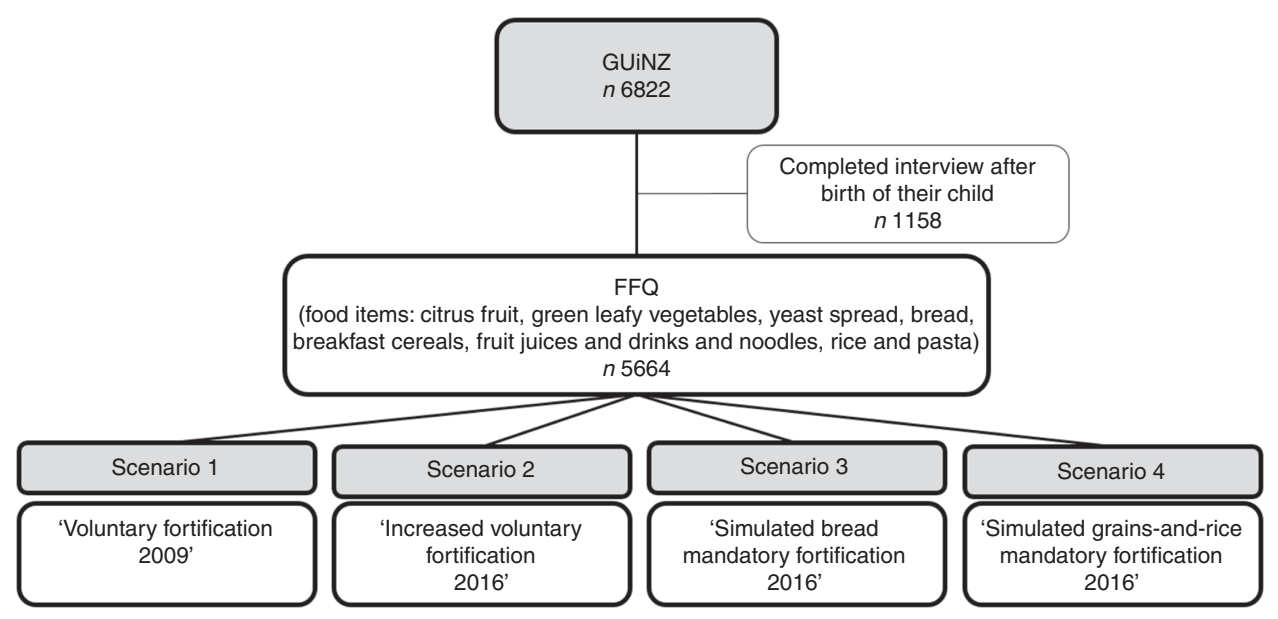

Fig. 1 Study flowchart. New Zealand, 2008-2010 (GUiNZ, Growing Up in New Zealand cohort study)

using as references the NZ Food Composition Tables of 2009 and $2016^{(28,29)}$. To facilitate the visualization of food DFE contributions, the following food items were grouped: breakfast cereal (high-fibre) and breakfast cereal (others); and citrus fruit and fruit juices and drinks.

For each of the four scenarios of folic acid fortification, total DFE intake was divided into tertiles and described according to the women's self-prioritized ethnicity. If ethnicity is not a factor associated with DFE intake, we expect to have $33 \%$ of each self-prioritized ethnicity (European, Māori, Pacific, Asian and Others) in each tertile of DFE intake. Binomial probability tests were used to compare statistical differences in proportions.

All analyses were performed using the statistical software package Stata release 12 (2011). Two-sided significance was determined at $P<0 \cdot 05$.

\section{Results}

Participants identified their ethnicity as European (56.0\%), Asian (14.2\%), Māori (13.2\%), Pacific (12.8\%) or Others $(3.8 \%)$. Over half of the women $(56.4 \%)$ were more than 29 years old, and over half (59.5\%) had BMI $\leq 24.9 \mathrm{~kg} / \mathrm{m}^{2}$. Approximately one-third (30.4\%) had completed at least a diploma/trade certificate, and approximately one-third $(37.7 \%)$ lived in neighbourhoods in the intermediate category of deprivation (deciles 4-7; Table 2).

\section{Non-intake of foods naturally bigh in folate, fortified or suitable for fortification with folic acid} Of the foods naturally high in folate, fortified or suitable for fortification with folic acid, the most frequently consumed were bread, green leafy vegetables, and noodles, rice and pasta, followed by fruit juices and drinks, citrus fruit, breakfast cereal (high-fibre), yeast spread and other breakfast cereals. Non-intake of these foods varied according to some of the women's sociodemographic characteristics (Table 2). However, the non-intake of bread did not vary by maternal education or BMI, or by neighbourhood deprivation; and the non-intake of green leafy vegetables and citrus fruit did not vary by maternal BMI or ethnicity, respectively (Table 2).

\section{Foods naturally high in folate, fortified or suitable for fortification with folic acid compared with NZ Food Composition Tables of 2009 and 2016}

From 2009 to 2016, the amount of DFE increased for citrus fruit by $111 \%$, green leafy vegetables by $32 \%$, fruit juices and drinks by $64 \%$, yeast spread by $48 \%$, bread by $25 \%$, breakfast cereal (high-fibre) by $75 \%$, breakfast cereal (others) by $56 \%$, and noodles, rice and pasta by $59 \%$ (Table 1). These increases in DFE content in foods naturally high in folate may have occurred due to the increase in the number of imported products in NZ from 2009 to 2016. The maximum amount of DFE in bread increased from $293 \mu \mathrm{g} / 100 \mathrm{~g}$ in 2009 to $820 \mu \mathrm{g} /$ $100 \mathrm{~g}$ in 2016. The maximum amount of DFE in breakfast cereals increased from $333 \mu \mathrm{g} / 100 \mathrm{~g}$ in 2009 to $1300 \mu \mathrm{g}$ and $850 \mu \mathrm{g} / 100 \mathrm{~g}$ in 2016 for the high-fibre and other breakfast cereal types, respectively. The maximum amount of DFE in the available brands of yeast spread increased from $2000 \mu \mathrm{g} /$ $100 \mathrm{~g}$ in 2009 to $3300 \mu \mathrm{g} / 100 \mathrm{~g}$ in 2016 (see online supplementary material, Supplemental Table 1).

\section{Main contributors of dietary folate equivalents intake according to self-prioritized etbnicity and scenarios of food fortification with folic acid} In the 'voluntary fortification 2009' scenario, bread (26\%), breakfast cereals (26\%) and yeast spread (21\%) were the three largest food sources of DFE for the entire sample. Green leafy vegetables were the main contributor of DFE for Asian women (30\%) and the third contributor for Others (20\%). In the 'increased voluntary fortification 2016' scenario, breakfast cereals (30\%) became the main contributor of DFE dietary intake, followed by bread (22\%) and yeast spread (21\%) for the entire sample. As expected, bread became the main contributor of DFE 
Table 2 Prevalence of non-intake of foods naturally high in folate, fortified or suitable for fortification with folic acid consumed by pregnant women in New Zealand according to sociodemographic characteristics. New Zealand, 2008-2010

\begin{tabular}{|c|c|c|c|c|c|c|c|c|c|c|}
\hline \multirow[b]{3}{*}{ Characteristic } & \multicolumn{10}{|c|}{ Naturally high in folate, fortified or suitable for fortification with folic acid } \\
\hline & \multicolumn{2}{|c|}{ Total } & \multirow{2}{*}{$\frac{\begin{array}{c}\text { Citrus } \\
\text { fruit }\end{array}}{(\%)}$} & \multirow{2}{*}{$\begin{array}{c}\text { Green leafy } \\
\text { vegetables }\end{array}$} & \multirow{2}{*}{$\begin{array}{l}\text { Fruit juices } \\
\text { and drinks } \\
\frac{(\%)}{}\end{array}$} & \multirow{2}{*}{$\begin{array}{c}\begin{array}{c}\text { Yeast } \\
\text { spread }\end{array} \\
(\%)\end{array}$} & \multirow{2}{*}{$\begin{array}{c}\text { Bread } \\
(\%)\end{array}$} & \multirow{2}{*}{$\begin{array}{c}\begin{array}{c}\text { Breakfast } \\
\text { cereal } \\
\text { (high-fibre) }\end{array} \\
(\%)\end{array}$} & \multirow{2}{*}{$\begin{array}{c}\begin{array}{c}\text { Breakfast } \\
\text { cereal } \\
\text { (others) }\end{array} \\
(\%)\end{array}$} & \multirow{2}{*}{$\begin{array}{c}\begin{array}{c}\text { Noodles } \\
\text { rice and } \\
\text { pasta }\end{array} \\
(\%)\end{array}$} \\
\hline & $n$ & $\%$ & & & & & & & & \\
\hline Total & 5664 & 100 & $14 \cdot 1$ & 4.9 & $12 \cdot 5$ & $39 \cdot 3$ & $1 \cdot 1$ & $28 \cdot 1$ & $56 \cdot 5$ & 7.5 \\
\hline \multicolumn{11}{|l|}{ Self-prioritized ethnicity } \\
\hline European & 3168 & $56 \cdot 0$ & $14 \cdot 3$ & $5 \cdot 1$ & $9 \cdot 7$ & $24 \cdot 3$ & 0.5 & 19.9 & $62 \cdot 1$ & $6 \cdot 4$ \\
\hline Māori & 747 & $13 \cdot 2$ & $16 \cdot 5$ & $5 \cdot 2$ & $15 \cdot 7$ & $32 \cdot 4$ & $<1.4 \|$ & $27 \cdot 7$ & $42 \cdot 0$ & $10 \cdot 2$ \\
\hline Pacific & 726 & $12 \cdot 8$ & $13 \cdot 8$ & $6 \cdot 2$ & 14.6 & $55 \cdot 0$ & $<1.4 \|$ & 36.5 & 39.0 & $13 \cdot 2$ \\
\hline Asian & 802 & $14 \cdot 2$ & $12 \cdot 0$ & $2 \cdot 7$ & $18 \cdot 4$ & 84.5 & 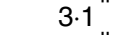 & $52 \cdot 1$ & 64.4 & $4 \cdot 1$ \\
\hline Otherst & 213 & 3.8 & $12 \cdot 7$ & $<4.7 \|$ & 14.6 & $62 \cdot 0$ & $<4.7 \|$ & $32 \cdot 6$ & 61.5 & 6.6 \\
\hline$P$ value* & & & $0 \cdot 138$ & $0.010^{\prime \prime}$ & $\leq 0.001$ & $\leq 0.001$ & $\leq 0.001$ & $\leq 0.001$ & $\leq 0.001$ & $\leq 0.001$ \\
\hline \multicolumn{11}{|l|}{ Age (years) } \\
\hline$<20$ & 273 & 4.8 & $25 \cdot 4$ & 11.7 & 12.5 & $45 \cdot 1$ & $<3.7 \|$ & 42.5 & 39.6 & $16 \cdot 5$ \\
\hline $20-29$ & 2195 & $38 \cdot 8$ & $14 \cdot 6$ & $6 \cdot 6$ & 11.0 & 43.5 & 1.4 & 34.8 & $51 \cdot 7$ & $9 \cdot 3$ \\
\hline$>29$ & 3196 & $56 \cdot 4$ & $12 \cdot 8$ & $3 \cdot 1$ & $13 \cdot 6$ & 35.9 & 0.8 & $22 \cdot 4$ & 61.4 & 5.5 \\
\hline$P$ value $*$ & & & $\leq 0.001$ & $\leq 0.001$ & 0.018 & $\leq 0.001$ & 0.041 & $\leq 0.001$ & $\leq 0.001$ & $\leq 0.001$ \\
\hline \multicolumn{11}{|l|}{ Level of education } \\
\hline Higher degree & 950 & $16 \cdot 8$ & $10 \cdot 5$ & $2 \cdot 3$ & $11 \cdot 8$ & $37 \cdot 3$ & 1.2 & $18 \cdot 1$ & $65 \cdot 7$ & 3.8 \\
\hline Bachelor's degree & 1308 & $23 \cdot 1$ & $10 \cdot 7$ & $2 \cdot 7$ & 9.5 & $37 \cdot 3$ & 1.0 & 23.0 & $62 \cdot 5$ & $5 \cdot 1$ \\
\hline $\begin{array}{l}\text { Diploma/trade certificate/ } \\
\text { NCEA 5-6 }\end{array}$ & 1717 & $30 \cdot 4$ & 14.9 & $4 \cdot 8$ & $12 \cdot 6$ & $37 \cdot 6$ & $1 \cdot 2$ & $30 \cdot 4$ & $52 \cdot 3$ & $7 \cdot 1$ \\
\hline $\begin{array}{l}\leq \text { Secondary school/ } \\
\text { NCEA 1-4 }\end{array}$ & 1678 & $29 \cdot 7$ & $18 \cdot 1$ & $8 \cdot 1$ & $15 \cdot 3$ & $43 \cdot 7$ & 1.0 & $35 \cdot 5$ & $51 \cdot 3$ & 11.9 \\
\hline$P$ value ${ }^{*}$ & & & $\leq 0.001$ & $\leq 0.001$ & $\leq 0.001$ & $\leq 0.001$ & 0.954 & $\leq 0.001$ & $\leq 0.001$ & $\leq 0.001$ \\
\hline \multicolumn{11}{|l|}{ BMl } \\
\hline$\leq 24.9 \mathrm{~kg} / \mathrm{m}^{2}$ & 3000 & 59.5 & 11.4 & $4 \cdot 2$ & 11.4 & $40 \cdot 2$ & 1.1 & $25 \cdot 1$ & $60 \cdot 1$ & $6 \cdot 0$ \\
\hline $25.0-29.9 \mathrm{~kg} / \mathrm{m}^{2}$ & 1136 & 22.5 & $14 \cdot 8$ & $5 \cdot 0$ & $12 \cdot 1$ & $32 \cdot 8$ & 0.9 & $27 \cdot 8$ & 58.9 & $6 \cdot 9$ \\
\hline$\geq 30.0 \mathrm{~kg} / \mathrm{m}^{2}$ & 907 & $18 \cdot 0$ & $18 \cdot 6$ & $4 \cdot 3$ & 14.7 & 38.6 & $<1 \cdot 1 \|$ & 31.0 & 48.7 & $9 \cdot 1$ \\
\hline $\bar{P}$ value* & & & $\leq 0.001$ & 0.486 & 0.028 & $\leq 0.001$ & 0.412 & 0.001 & $\leq 0.001$ & 0.005 \\
\hline \multicolumn{11}{|l|}{ Neighbourhood deprivation§ } \\
\hline 1-3 (least deprived) & 1459 & $25 \cdot 8$ & $12 \cdot 6$ & $3 \cdot 6$ & $10 \cdot 3^{*}$ & $30 \cdot 7$ & 0.8 & $22 \cdot 4$ & 63.4 & 4.8 \\
\hline $4-7$ & 2133 & 37.7 & $13 \cdot 3$ & 4.5 & $11 \cdot 8$ & $37 \cdot 6$ & 0.9 & $25 \cdot 7$ & 59.5 & 6.9 \\
\hline 8-10 (most deprived) & 2070 & 36.5 & $16 \cdot 1$ & $6 \cdot 1$ & $15 \cdot 0$ & $47 \cdot 2$ & 1.4 & 34.7 & $48 \cdot 8$ & $10 \cdot 0$ \\
\hline$P$ value ${ }^{*}$ & & & 0.006 & 0.002 & $\leq 0.001$ & $\leq 0.001$ & 0.192 & $\leq 0.001$ & $\leq 0.001$ & $\leq 0.001$ \\
\hline
\end{tabular}

NCEA, National Certificate of Educational Achievement.

${ }^{*} P$ values were calculated by $X^{2}$ test, $P<0.05$ identified statistically significant differences.

tOthers includes maternal self-prioritized ethnicities of Middle Eastern, Latin American and African (MELAA) and Other.

łBased on BMI: underweight and eutrophic, BMI $\leq 24.9 \mathrm{~kg} / \mathrm{m}^{2}$; overweight, BMI $=25.0-29.9 \mathrm{~kg} / \mathrm{m}^{2} ;$ obese, BMI $\geq 30.0 \mathrm{~kg} / \mathrm{m}^{2}$

$\S$ Area-level socio-economic deprivation was measured using the 2006 New Zealand Index of Deprivation (NZDep06), grouped as deciles.

$\|$ To protect the anonymity of the study participants, cells with low numbers are indicated as below the percentage equivalent to ten individuals.

intake in the 'simulated bread mandatory fortification 2016' scenario for the whole sample and ethnic groups, except for Europeans (for whom breakfast cereals represented the main source of DFE). In the 'simulated grainsand-rice mandatory fortification 2016' scenario, bread remained the main contributor of DFE intake for the entire sample. However, the main contributor of DFE intake for Asian women were noodles, rice and pasta, as was breakfast cereal for European women (Fig. 2).

Dietary folate equivalents intake according to level of intake, self-prioritized ethnicity and scenarios of food fortification with folic acid

Figure 3 shows the proportion of women, according to their self-prioritized ethnicity and tertile of DFE intake, for the four scenarios of food fortification with folic acid. The proportions in the lowest tertile of DFE intake in the first three fortification scenarios were Asians (58-60\%),
Others (43-44\%), Europeans (31-32\%), Pacific (23$26 \%$ ) and Māori (23-24\%). In the 'simulated grains-andrice mandatory fortification 2016' scenario, the proportions in the lowest DFE intake tertile were Asians (39\%), Others (41\%), Europeans (37\%), Pacific (23\%) and Māori (27\%). In the first three scenarios, the proportion varied in comparisons between all ethnic groups except for Pacific $v$. Māori $(P=0.54,0.17$ and 0.93 , respectively). In the fourth scenario, the proportions of Asian and Others did not differ from one another $(P=0 \cdot 28)$, but both were higher than for the other three ethnic groups.

In comparisons within each ethnic group across the scenarios, no differences were present for the first three scenarios. In contrast, with the 'simulated grains-and-rice mandatory fortification 2016' scenario, the proportion of those with Asian ethnicity decreased in the lowest $(P<0.001)$ and increased in the middle $(P<0.001)$ and 

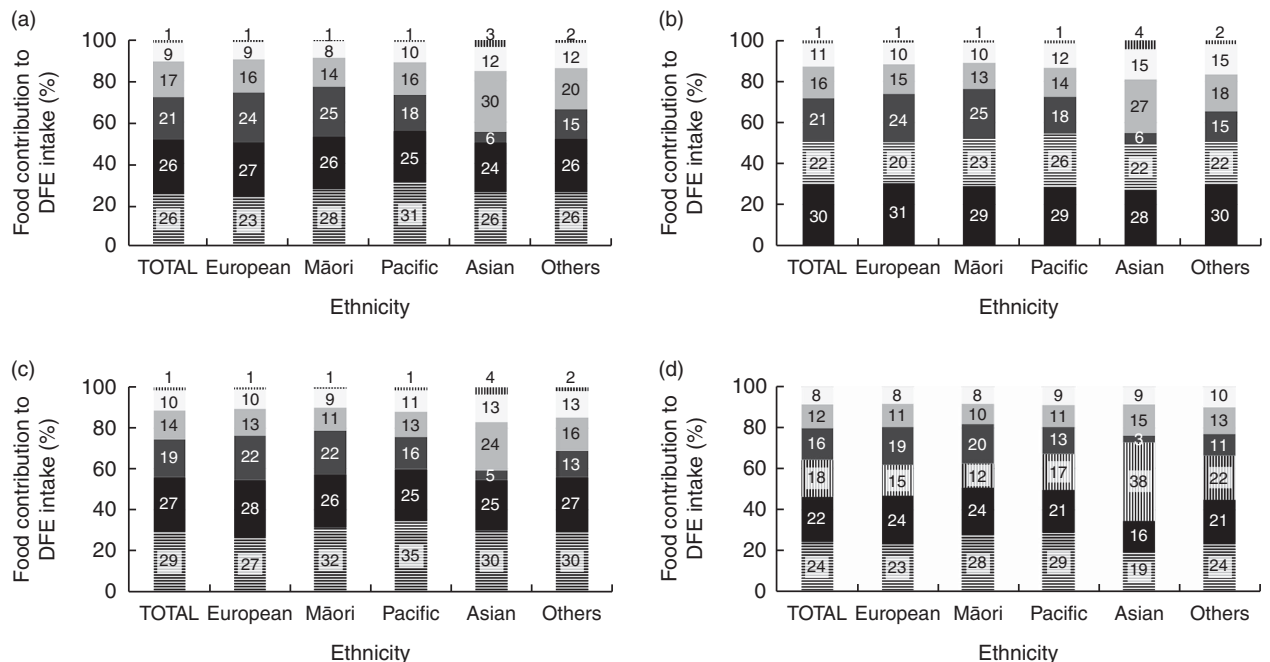

Fig. 2 Percentage food contributions to dietary folate equivalents (DFE) intake from foods naturally high in folate, fortified or suitable for fortification with folic acid (三, bread; $\square$, breakfast cereals*; $\square$, yeast spread; $\cdots$, green leafy vegetables; , citrus fruit, fruit juices and drinks; III, noodles, rice and pasta), according to women's ethnicity $\dagger$ and scenarios of food fortification with folic acid (a, 'voluntary fortification 2009'; b, 'voluntary fortification 2016'; c, 'simulated bread mandatory fortification 2016'; d, 'simulated grainsand-rice mandatory fortification 2016') in New Zealand, 2008-2010. *The food items breakfast cereal (high-fibre) and breakfast cereal (others) were grouped to facilitate the visualization of food contributions; the food items citrus fruit and fruit juices and drinks were grouped as well. †Others includes maternal self-prioritized ethnicities of Middle Eastern, Latin American and African (MELAA) and Other

highest $(P<0 \cdot 001)$ tertiles of DFE intake; for European the proportion increased in the lowest $(P<0 \cdot 001)$ and decreased in the middle $(P=0.03)$ and highest $(P<0.001)$ tertiles of DFE intake; and for Māori the proportion decreased in the highest tertile of DFE intake $(P=0 \cdot 01)$.

\section{Discussion}

Among the foods naturally high in folate or fortified with or suitable for fortification with folic acid, bread, green leafy vegetables, noodles, rice and pasta, and fruit juices and drinks were the items consumed by more than $80 \%$ of the pregnant women, independent of their sociodemographic characteristics. On average, the amount of folic acid in the fortified food products increased from 2009 to 2016: by $56-75 \%$ for breakfast cereals, $48 \%$ for yeast spreads and $25 \%$ for breads. In the scenario of 'increased voluntary fortification 2016', breakfast cereal was the main contributor of DFE intake, followed by bread and yeast spread. In descending order, the proportions of different ethnic groups in the lowest tertile of DFE intake for the four fortification scenarios were Asians (39-60\%), Others (41-44\%), Europeans (31-37\%), Pacific (23-26\%) and Māori (23-27\%). However, in comparisons within each ethnic group across the scenarios of food fortification with folic acid, differences were observed only with the 'simulated grains-and-rice mandatory fortification 2016' scenario.

The discussion about mandatory fortification of staple foods with folic acid in NZ has raised arguments in favour ${ }^{(16,33,38-44)}$ and against ${ }^{(41,45-47)}$ its implementation.
There are concerns regarding the potential toxic effects of excessive folic acid intake among children and adolescents, as well as among the elderly, due to the irreversible neurological damage caused by masked vitamin $\mathrm{B}_{12}$ deficiency which can occur with high intakes of folic $\operatorname{acid}^{(46)}$. Furthermore, there is concern about the possibility of potential adverse effects of unmetabolized folic acid intake, either from fortified foods or from supplements, or both $^{(48)}$. A lifelong exposure to increased amounts of synthetic folate is also hypothesized to increase the risk of cancer $^{(41,46)}$. Alternative strategies, for example improving adherence among pregnant women to the national recommendations for folic acid supplementation, remains a challenge in NZ and worldwide. In NZ the risk of NTD shows socio-economic and ethnic gradients. Māori women are at higher risk than those of non-Māori non-Pacific ethnicity (relative risk $=2 \cdot 65 ; 95 \%$ CI $1.64,4 \cdot 29)^{(33,42,49-51)}$. NTD are significantly more common in world regions with voluntary $v$. mandatory folic acid fortification ${ }^{(13)}$. In addition to the reduction in NTD rates, the mandatory approach and the consequent higher dietary folate intakes have been shown to be associated with reduced risks of other diseases, including anaemia, CVD, hypertension, neuropsychiatric disorders, cancers and other congenital defects such as heart anomalies and clefts, although the causality of these relationships remains unproven ${ }^{(41,52-54)}$. So far, studies conducted in countries where mandatory fortification was implemented have not shown any potential negative effects of this policy ${ }^{(55)}$. A metaanalyses of data on 50000 individuals (mean age 64 (SD 10) years) found that folic acid supplementation was not associated with the incidence of cancer of the large 
(a)

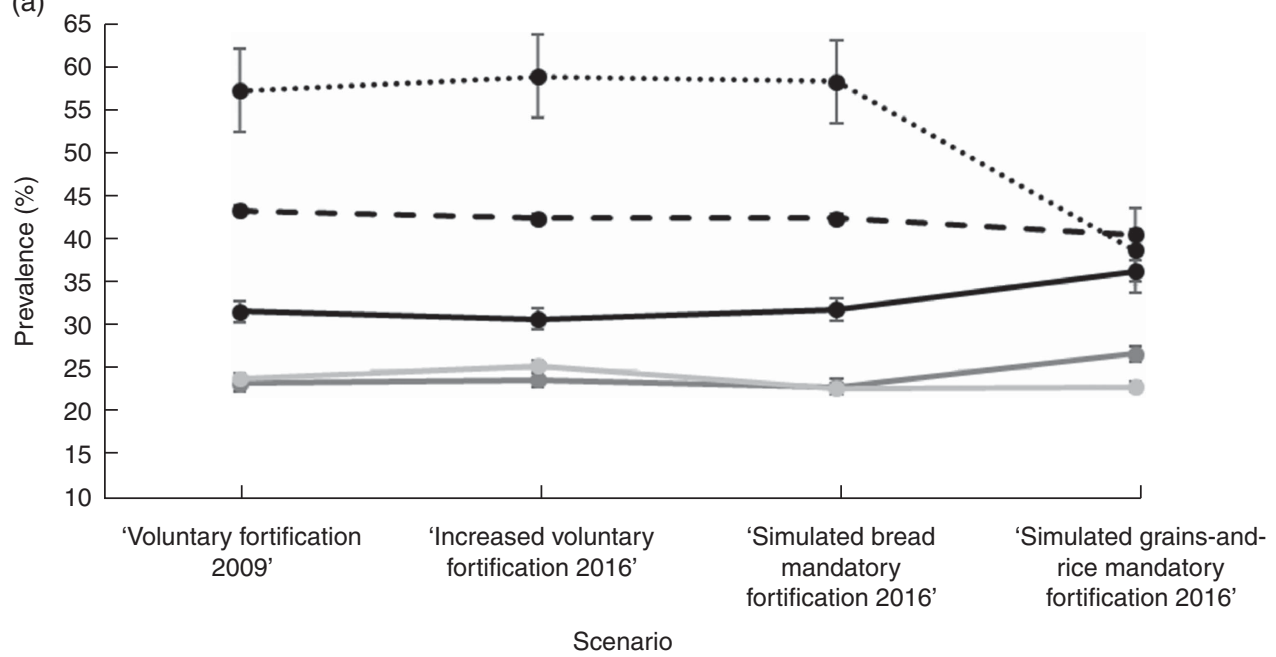

(b)

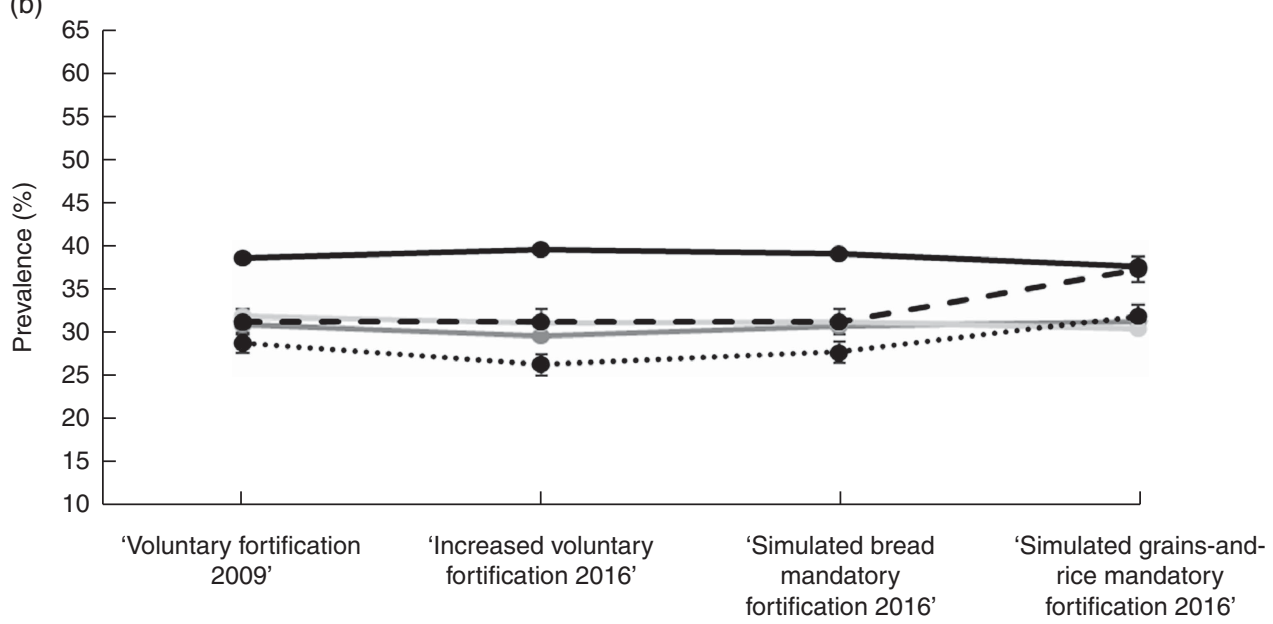

Scenario

(c)

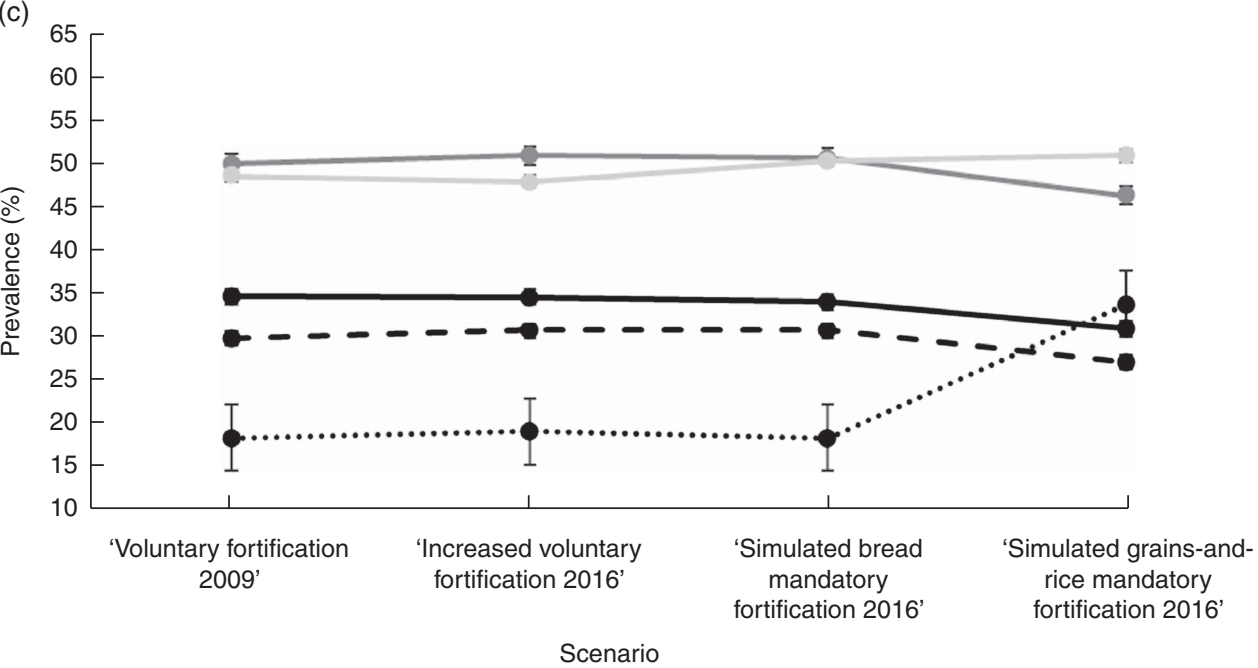

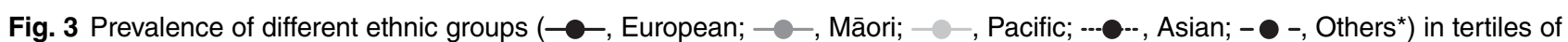
dietary folate equivalents (DFE) intake (a, lowest tertile of DFE intake; b, middle tertile of DFE intake; c, highest tertile of DFE intake) according to the scenarios of food fortification with folic acid in New Zealand, 2008-2010. *Others includes maternal self-prioritized ethnicities of Middle Eastern, Latin American and African (MELAA) and Other 
intestine, prostate, lung, breast or any other specific site during the first 5 years of folic acid supplementation, indicating that the smaller dose provided by fortification programmes potentially would not affect the risk of cancer development as well ${ }^{(55)}$. Recently in NZ, in response to a request by the Ministry of Health, the Prime Minister's Chief Science Advisor and the Royal Society Te Aparangi completed a review which concluded that the benefits of mandatory fortification of packaged bread with folic acid outweigh any potential adverse effects. Analyses from 2012 suggest that moving from a hypothetical voluntary programme in which $50 \%$ of all packaged breads in NZ are fortified to a mandatory programme in which $100 \%$ of packaged breads are fortified would prevent approximately 5-15 extra NTD pregnancies annually ${ }^{(18)}$.

The economic benefit from the prevention of NTD has been shown to exceed the cost of mandatory folic acid fortification in the USA (benefit-cost ratio $=4 \cdot 3: 1$ ), Chile $(11 \cdot 8: 1)$ and South Africa $(30: 1)^{(2)}$. In that review, the only study where mandatory fortification was not cost-effective was a simulation study using NZ data ${ }^{(46)}$. This may be the result of the lack of robust data about the costs involved in mandatory fortification for NZ, with wide variation in the costs estimated by the Food Standards Australia New Zealand-commissioned consultant and by the flour industry $^{(30,47)}$.

According to the NZ Food Composition Tables 2016, the content of folic acid in breakfast cereals varied from 0 to $585 \mu \mathrm{g}$ folic acid per serving ( $45 \mathrm{~g}$ of breakfast cereal), 4.5 times higher than the permitted ${ }^{(29)}$. In 2009 , an evaluation made by the NZ Food Safety Authority showed that the amount of folic acid added to breakfast cereals was between 88 and $374 \mu \mathrm{g}$ folic acid per serving, indicating both wide variability and excessive content in some breakfast cereals ${ }^{(56)}$. Similar observations were made for yeast spread $(8560 \mu \mathrm{g} / 100 \mathrm{~g})$, with folate concentration more than four times higher than the permitted and what the label claimed $(2000 \mu \mathrm{g} / 100 \mathrm{~g})^{(56)}$. The NZ legislation for voluntary folic acid fortification that was in place until June 2018 could potentially exceed the upper limit of intake for individuals in the higher end of intake of fortified breakfast cereals or yeast spreads (without considering other sources of folate) representing, approximately, $1 \%$ of different NZ population groups ${ }^{(56)}$.

A retrospective survey of 723 postpartum women from hospitals and birth centres across NZ showed that mandatory fortification of bread with folic acid would benefit the sectors of the population less likely to use folic acid supplements. However, it also identified that this type of fortification would not benefit subgroups equally, indicating that, with bread fortification, Māori women were more likely to achieve an adequate intake of folate than women of Pacific, Asian and other ethnicities ${ }^{(39)}$. Studies have suggested that, in NZ, the proposed bread mandatory fortification is probably an outdated policy intervention $^{(16,33,39,57)}$. When comparing data from 1997 and 2008/
09, NZ adults were less likely in 2008/09 to report consuming vegetables, bread, breakfast cereal, pies, biscuits, cakes and puddings and more likely to report consuming rice dishes ${ }^{(58)}$. Among females, there was an increased reporting of intakes of snacks, snack bars and pasta from 1997 to 2008/09 ${ }^{(58)}$. The change in the dietary intake over time among NZ adults was probably influenced by the increase in the population diversity from the 2000s and, consequently, in the variety of foods that were available $^{(59)}$.

The mandatory fortification of flour is a simpler intervention: there is an extensive knowledge of adding $B$ vitamins to cereals (including wheat and maize flours) and rice grains, and there are only a small number of flour millers supplying the NZ market ${ }^{(20,60,61)}$. Furthermore, this approach would provide more options for consumers ${ }^{(60)}$. Rice can be more difficult to fortify because usually the supply is produced at a small scale, but the NZ case needs to be further studied ${ }^{(20)}$. If vitamin $\mathrm{B}_{12}$ deficiency is a concern in NZ, this nutrient could also be added to fortified flours ${ }^{(20)}$.

The monitoring and evaluation of a health policy are crucial to identify if it is implemented as planned and if it does more good than harm ${ }^{(59,62,63)}$. The fortification of staple foods with folic acid in NZ should include updated, adequate and continued monitoring of NTD ${ }^{(64)}$, and also monitoring of the potential negative outcomes that could be associated with excessive folic acid intake, such as toxicity symptoms (mainly in children and adolescents) ${ }^{(46,60)}$, vitamin $\mathrm{B}_{12}$ deficiency (mostly among the elderly) ${ }^{(46,60)}$ and cancer risk ${ }^{(65)}$. As part of the baseline and monitoring assessment, only updated national nutrition surveys, ideally with assessment of red-blood-cell folate levels ${ }^{(60)}$, will allow for estimation on the prevalence of inadequate and excess folic acid intakes across lifecycle groups ${ }^{(16,59,62-64,66)}$. Also, regulating and evaluating the amount of folic acid added to the permitted foods is needed with some urgency in NZ.

To our knowledge, the present study is the first in NZ to simulate the impact of different scenarios of food fortification with folic acid on the dietary intake of women from different ethnic groups in a generalizable birth cohort study $^{(22,67)}$. Therefore, we add important findings to the discussion around the development of a mandatory food fortification programme with folic acid. One potential limitation of the study is the use of a non-validated FFQ to evaluate maternal dietary folate intake during pregnancy. However, as previously described, the FFQ used included the main dietary sources of folate for pregnant women in $\mathrm{NZ}^{(16,23,28)}$. It is also important to consider the potential sources of error in the estimated DFE intake due to the assumptions on portion sizes and DFE content of foods consumed. The FFQ food list lacked detailed information about food brands. However, we did use a countryspecific food composition database with more than 2500 foods, where the majority of nutrient data is obtained by 
analysis of composite samples $(76 \%)^{(68)}$. Moreover, the individual quantitative data on DFE dietary intake have not been presented and all the analyses reported herein were based on classification of individuals according to their ranking of DFE intake.

\section{Conclusion}

The present study demonstrated that the current voluntary fortification of food with folic acid in NZ is not providing equal access to folate intake among its ethnically diverse population of women of childbearing age. The recent recommendation of mandatory fortification of breads in NZ may not be enough to reduce inequalities in DFE intakes. If the mandatory fortification with folic acid is extended for grains and rice in NZ, intakes of folate would be more evenly distributed among women of different ethnicities. Furthermore, there is an urgent need to regulate and evaluate the amount of folic acid added to the permitted foods.

\section{Acknowledgements}

Acknowledgements: The authors would like to acknowledge the participants of the GUiNZ study. They would also like to acknowledge the funders, the New Zealand Ministry of Social Development, supported by the Health Research Council, as well as the ongoing support from Auckland UniServices and The University of Auckland. They acknowledge all members of the GUiNZ team, including those members and managers of the operational, data, communications, community and quality aspects of the study. The authors are grateful for the ongoing support and advice provided by their Kaitiaki Group and their national and international Scientific Advisory Group, and also acknowledge the members of the Morton Consortium responsible for planning and design of this study in the Development Phase. Additionally, they acknowledge the São Paulo Research Foundation (FAPESP, Brazil) for supporting J.A.T. (grant number 2016/15356-3). Financial support: GUiNZ has been funded by the New Zealand Ministries of Social Development, Health, Education, Justice and Pacific Island Affairs; the former Ministry of Science Innovation and the former Department of Labour (now both part of the Ministry of Business, Innovation and Employment); the former Ministry of Women's Affairs (now the Ministry for Women); the Department of Corrections; the Families Commission (now known as the Social Policy Evaluation and Research Unit); Te Puni Kokiri; New Zealand Police; Sport New Zealand; the Housing New Zealand Corporation; and the former Mental Health Commission, The University of Auckland and Auckland UniServices Limited. Other support for the study has been provided by the NZ Health
Research Council, Statistics New Zealand, the Office of the Children's Commissioner and the Office of Ethnic Affairs. J.A.T. is supported by FAPESP, Brazil (grant 2016/ 15356-3). The funding agencies had no role in the design, analysis or writing of this article. Conflict of interest: None. Authorship: S.M.B.M., C.C.G., C.R.W. and S.B. were involved in the conception and design of the study; J.A.T. conducted the data analysis; J.A.T., T.G.C., C.R.W., C.C.G. and D.M.M. contributed to interpretation of data and manuscript development. All authors participated in critically revising the manuscript and approved the final version. Ethics of human subject participation: This study was conducted according to the guidelines laid down in the Declaration of Helsinki and all procedures involving human subjects were approved by Ministry of Health Northern Y Regional Ethics Committee. Written informed consent was obtained from all participating women.

\section{Supplementary material}

To view supplementary material for this article, please visit https://doi.org/10.1017/S1368980018003026

\section{References}

1. Copp AJ, Stanier P \& Greene NDE (2013) Neural tube defects: recent advances, unsolved questions, and controversies. Lancet Neurol 12, 799-810.

2. Yi Y, Lindemann M, Colligs A et al. (2011) Economic burden of neural tube defects and impact of prevention with folic acid: a literature review. Eur J Pediatr 170, 1391-1400.

3. Arth A, Kancherla V, Pachón H et al. (2016) A 2015 global update on folic acid-preventable spina bifida and anencephaly. Birth Defects Res Part A Clin Mol Teratol 106, 520-529.

4. Mitchell LE (2005) Epidemiology of neural tube defects. Am J Med Genet C Semin Med Genet 135C, 88-94.

5. Rasmussen SA, Chu SY, Kim SY et al. (2008) Maternal obesity and risk of neural tube defects: a metaanalysis. $\mathrm{Am} \mathrm{J}$ Obstet Gynecol 198, 611-619.

6. Soler NG, Walsh CH \& Malins JM (1976) Congenital malformations in infants of diabetic mothers. Q J Med $\mathbf{4 5}$, 303-313.

7. Moretti ME, Bar-Oz B, Fried S et al. (2005) Maternal hyperthermia and the risk for neural tube defects in offspring: systematic review and meta-analysis. Epidemiology 16, 216-219.

8. Missmer SA, Suarez L, Felkner M et al. (2006) Exposure to fumonisins and the occurrence of neural tube defects along the Texas-Mexico border. Environ Health Perspect 114, 237-241.

9. MRC Vitamin Study Research Group (1991) Prevention of neural tube defects: Results of the Medical Research Council Vitamin Study. Lancet 338, 131-137.

10. Gomes S, Lopes C \& Pinto E (2016) Folate and folic acid in the periconceptional period: recommendations from official health organizations in thirty-six countries worldwide and WHO. Public Health Nutr 19, 176-189.

11. Abramsky L, Botting B, Chapple J et al. (1999) Has advice on periconceptional folate supplementation reduced neural-tube defects? Lancet 354, 998-999. 
12. Williams J, Mai CT, Mulinare J et al. (2015) Updated estimates of neural tube defects prevented by mandatory folic acid fortification - United States, 1995-2011. MMWR Morb Mortal Wkly Rep 64, 1-5.

13. Atta CAM, Fiest KM, Frolkis AD et al. (2016) Global birth prevalence of spina bifida by folic acid fortification status: a systematic review and meta-analysis. Am J Public Health 106, e24-e34.

14. Hertrampf E \& Cortés F (2008) National food-fortification program with folic acid in Chile. Food Nutr Bull 29, 2 Suppl., S231-S237.

15. Australian Institute of Health and Welfare (2016) Monitoring the Health Impacts of Mandatory Folic Acid and Iodine Fortification. http://www.aihw.gov.au/WorkArea/Down loadAsset.aspx?id=60129555568 (accessed May 2017).

16. Evans SE, Mygind VL, Peddie MC et al. (2014) Effect of increasing voluntary folic acid food fortification on dietary folate intakes and adequacy of reproductive-age women in New Zealand. Public Health Nutr 17, 1447-1453.

17. Ministry for Primary Industries (2012) Voluntary Folic Acid Fortification: Monitoring and Evaluation Report. vol. 3. https://www.mpi.govt.nz/document-vault/4163 (accessed October 2018).

18. Office of the Prime Minister's Chief Science Advisor \& Royal Society Te Aparangi (2018) The Health Benefits and Risks of Folic Acid Fortification of Food. http://www.pmcsa.org.nz/ wp-content/uploads/The-health-benefits-and-risks-of-folicacid-fortification-of-food.pdf (accessed October 2018).

19. World Health Organization, Food and Agriculture Organization of the United Nations, UNICEF et al. (2009) Recommendations on Wheat and Maize Flour Fortification. Meeting Report: Interim Consensus Statement. Geneva: WHO; available at http://www.who.int/nutrition/publica tions/micronutrients/wheat_maize_fort.pdf

20. World Health Organization \& Food and Agriculture Organization of the United Nations (2006) Guidelines on Food Fortification with Micronutrients [L Allen, B de Benoist, O Daryo et al., editors]. Geneva: WHO.

21. Hsiung DT, Marsit CJ, Houseman EA et al. (2007) Global DNA methylation level in whole blood as a biomarker in head and neck squamous cell carcinoma. Cancer Epidemiol Biomarkers Prev 16, 108-114.

22. Morton SMB, Atatoa Carr PE, Grant CCC et al. (2013) Cohort profile: Growing Up in New Zealand. Int J Epidemiol $\mathbf{4 2}$, 65-75.

23. Ministry of Health (2006) Food and Nutrition Guidelines for Healthy Pregnant and Breastfeeding Women: A Background Paper. Wellington: Ministry of Health.

24. Morton S, Grant CC, Wall CR et al. (2014) Adherence to nutritional guidelines in pregnancy: evidence from the Growing Up in New Zealand birth cohort study. Public Health Nutr 17, 1919-1929.

25. University of Otago \& Ministry of Health (2011) Methodology Report for the 2008/09 New Zealand Adult Nutrition Survey. Wellington: Ministry of Health.

26. Cade J, Thompson R, Burley V et al. (2002) Development, validation and utilisation of food-frequency questionnaires a review. Public Health Nutr 5, 567-587.

27. Russell D, Parnell W, Wilson N et al. (1999) NZ Food: Food People: Key Results of the 1997 National Nutrition Survey. Wellington: Ministry of Health.

28. New Zealand Ministry of Health (2009) The Concise New Zealand Food Composition Tables, 8th ed. Wellington: Ministry of Health; available at http://www.moh.govt.nz/ notebook/nbbooks.nsf/0/2fa2c987c25e81fecc25762c0075a 805/\$FILE/Concise_8_Edition.pdf

29. New Zealand Ministry of Health (2016) The Concise New Zealand Food Composition Tables, 12th ed. Wellington: Ministry of Health; available at https://www.foodcomposi tion.co.nz/downloads/concise-12-edition.pdf
30. Food Standards Australia New Zealand (2006) Final Assessment Report: Proposal P295. Consideration of Mandatory Fortification with Folic Acid. Canberra: FSANZ; available at http://www.foodstandards.govt.nz/code/ proposals/documents/FAR_P295_Folic_Acid_Fortification_ Attachs_1_6.pdf

31. Statistics NZ (2007) Tatauranga Aotearoa. QuickStats about culture and identity - 2006 Census. https://www.stats.govt. nz/ (accessed August 2017).

32. Statistics New Zealand (2010) National Ethnic Population Projections: 2006 (base)-2026 update. http://www.stats. govt.nz/browse_for_stats/population/estimates_and_pro jections/NationalEthnicPopulationProjections_HOTP200626.aspx (accessed October 2018).

33. Houghton LA (2014) A country left behind: folic acid food fortification policy in New Zealand. N Z Med J 127, 6-9.

34. US Department of Agriculture, Agricultural Research Service (2011) USDA National Nutrient Database for Standard Reference, release 24. https://ndb.nal.usda.gov/ndb/ (accessed October 2018).

35. Statistics New Zealand (2009) Final Report of Review of the Official Ethnicity Statistical Standard. Wellington: Statistics New Zealand.

36. World Health Organization (2014) Obesity and Overweight. Fact Sheet no. 311. Geneva: WHO.

37. Brunner Huber LR (2007) Validity of self-reported height and weight in women of reproductive age. Matern Child Health I 11, 137-144.

38. Bower C (2003) Fortification of food with folic acid and the prevention of neural tube defects. $N Z \operatorname{Med} J \mathbf{1 1 6}$, U292.

39. Mallard SR, Gray AR \& Houghton LA (2012) Delaying mandatory folic acid fortification policy perpetuates health inequalities: results from a retrospective study of postpartum New Zealand women. Hum Reprod 27, 273-282.

40. Mallard SR \& Houghton LA (2012) Folate knowledge and consumer behaviour among pregnant New Zealand women prior to the potential introduction of mandatory fortification. Asia Pac J Clin Nutr 21, 440-449.

41. Marks R \& Potter JD (2010) New Zealand should have mandatory fortification of bread with folic acid: no. J Prim Health Care 2, 76-78.

42. Morton S, Grant C \& Carr P (2013) Too many left at risk by current folic acid supplementation use: evidence from Growing Up in New Zealand. Aust N Z J Public Health 37, 190-191.

43. Oakley G, Wald N \& Omenn G (2003) Provide the citizens of New Zealand the miracle of folic acid fortification. $N Z$ Med I 116, U302.

44. Oakley GGP, Weber MB, Bell KN et al. (2004) Scientific evidence supporting folic acid fortification of flour in Australia and New Zealand. Birth Defects Res Part A Clin Mol Teratol 70, 838-841.

45. Mann J \& Green T (2002) Hyperhomocysteinaemia: time to screen and treat? $N Z$ Med J 115, U197.

46. Skeaff M, Green T \& Mann J (2003) Mandatory fortification of flour? Science, not miracles, should inform the decision. $N$ $Z$ Med J 116, U303.

47. Dalziel K, Segal L \& Katz R (2010) Cost-effectiveness of mandatory folate fortification $v$. other options for the prevention of neural tube defects: results from Australia and New Zealand. Public Health Nutr 13, 566-578.

48. Barua S, Kuizon S \& Junaid MA (2014) Folic acid supplementation in pregnancy and implications in health and disease. I Biomed Sci 21, 77.

49. Craig E, McDonald G, Adams J et al. (2012) Te Obonge Ake: The Health of Maori Children and Young People with Chronic Conditions and Disabilities in New Zealand. Dunedin: New Zealand Child and Youth Epidemiology 
Service, University of Otago; available at https://ourarchive. otago.ac.nz/handle/10523/6133

50. European Surveillance of Congenital Anomalies (2009) Special Report: Prevention of Neural Tube Defects by Periconceptional Folic Acid Supplementation in Europe. http://www.eurocat-network.eu/content/Special-ReportNTD-3rdEd-Part-I.pdf (accessed April 2017)

51. Teixeira JA, Castro TG, Wall CR et al. (2018) Determinants of folic acid supplement use outside national recommendations for pregnant women: results from the Growing Up in New Zealand cohort study. Public Health Nutr 21, 2183-2192.

52. Cornel MC, Smit DJ de \& de Jong-van den Berg LTW (2005) Folic acid - the scientific debate as a base for public health policy. Reprod Toxicol 20, 411-415.

53. Ionescu-Ittu R, Marelli AJ, Mackie AS et al. (2009) Prevalence of severe congenital heart disease after folic acid fortification of grain products: time trend analysis in Quebec, Canada. BMJ 338, b1673.

54. Bentley TG, Weinstein MC, Willett WC et al. (2009) A costeffectiveness analysis of folic acid fortification policy in the United States. Public Health Nutr 12, 455-467.

55. Vollset SE, Clarke R, Lewington S et al. (2013) Effects of folic acid supplementation on overall and site-specific cancer incidence during the randomised trials: meta-analyses of data on 50,000 individuals. Lancet 381, 1029-1036.

56. New Zealand Food Safety Authority (2009) Fortification Overages of the Food Supply: Folate. https://www.mpi. govt.nz/dmsdocument/22603/ (accessed October 2018).

57. Mallard SR, Gray AR \& Houghton LA (2012) Periconceptional bread intakes indicate New Zealand's proposed mandatory folic acid fortification program may be outdated: results from a postpartum survey. BMC Pregnancy Childbirth 12, 8 .

58. Smith C, Gray AR, Mainvil LA et al. (2015) Secular changes in intakes of foods among New Zealand adults from 1997 to 2008/09. Public Health Nutr 18, 3249-3259.
59. Lawrence M (2005) Assessing the case for mandatory folate fortification: policy-making in the face of scientific uncertainties. Aust N Z J Public Health 29, 328-330.

60. Green T, Newton R \& Bourn D (2003) Estimated folic acid intakes from simulated fortification of the New Zealand food supply. $N Z$ Med J 116, U294.

61. World Health Organization (2016) WHO Guideline: Fortification of Maize Flour and Corn Meal with Vitamins and Minerals. Geneva: WHO.

62. Lawrence M (2005) Challenges in translating scientific evidence into mandatory food fortification policy: an antipodean case study of the folate-neural tube defect relationship. Public Health Nutr 8, 1235-1241.

63. Lawrence M \& Riddell L (2007) Mandatory fortification with folic acid - what would Hippocrates say? Aust Fam Physician 36, 69-70, 72, 75.

64. Ministry of Health (2003) Improving Folate Intake in New Zealand: Policy Implications. Wellington: Ministry of Health; available at http://www.moh.govt.nz/notebook/ nbbooks.nsf/0/19C76A786D58C8D6CC256DA4008038A6/ \$file/ImprovingFolate.pdf

65. Cole BF, Baron JA, Sandler RS et al. (2007) Folic acid for the prevention of colorectal adenomas: a randomized clinical trial. JAMA 297, 2351-2359.

66. Bradbury KE, Williams SM, Mann JI et al. (2016) Serum and erythrocyte folate status of New Zealand women of childbearing age following a countrywide voluntary programme by the baking industry to fortify bread with folic acid. Public Health Nutr 19, 2897-2905.

67. Morton SSMB, Ramke J, Kinloch J et al. (2015) Growing Up in New Zealand cohort alignment with all New Zealand births. Aust N Z J Public Health 39, 82-87.

68. Sivakumaran SS, Huffman L \& Sivakumaran SS (2016) The New Zealand Food Composition Database: a useful tool for assessing New Zealanders' nutrient intake. Food Chem 238 , $101-110$. 